\title{
100 años de Enfermería Universitaria
}

\section{0 years of University Nursing}

Lic. Severino Rubio Domínguez

Director de la Escuela Nacional de Enfermería y Obstetricia ENEO-UNAM.

Durante más de 100 años que tiene de origen la Educación Formal de Enfermería en México, pues antes de 1907 que se funda la carrera en el Hospital General ya existían actividades de capacitación institucionalizada, se han preparado un gran número de profesionistas universitarias de Enfermería, que constituyen más de cien generaciones mismas que han contribuido al desarrollo del sistema de servicios de salud, y de manera directa a la atención general y especializada que ha sido posible ofrecer a las personas enfermas en hospitales, clínicas y sanatorios, donde es imprescindible el papel de colaboración de la enfermera profesional, pero mucho más necesaria la función específica y exclusiva que influye en la recuperación de la salud y en la preservación de la misma, cuando enfermería logra cimentar prácticas de autocuidado a través de su función de educación y promoción de la salud.
Son más de 40 mil egresadas de la UNAM en niveles Técnico, Licenciatura, Postécnicos y Posgrado, las que han aportado con sus servicios a fundar las Instituciones que actualmente son un activo valioso del pueblo de México. Son esas generaciones las que han colaborado en millones de cirugías y servicios especializados que frecuentemente salvaron muchas vidas, y en su caso

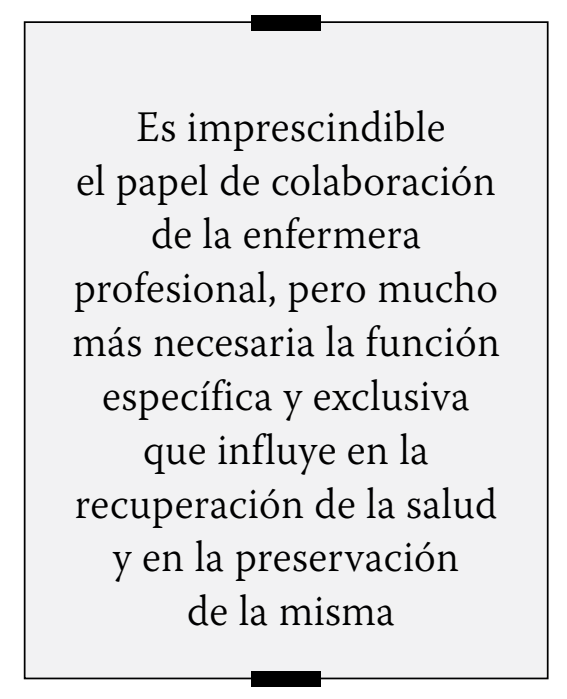

prolongaron calidad de vida cuando se enfrenta la enfermedad y el sufrimiento. Son esas generaciones las que en buen número cuidaron a miles de mujeres embarazadas y asistieron el nacimiento de miles de mexicanos.

Han sido miles las egresadas de la UNAM que se especializaron en cuidados intensivos, en pediatría, neonatología, como quirúrgicas, anestesistas, en salud pública, geriatría, enfermería neurológica, enfermería cardiológica, en nefrología, esterilización, en administración de servicios de salud y en docencia; seguramente suman más de treinta mil las especialistas que se educaron a través de sus programas en las mejores instituciones de servicios, desde que los primeros grupos se formaban en el Hospital General de México y el Hospital Juárez de México, hasta ahora que se forman en el gran campo de servicios del IMSS, ISSSTE, PEMEX, Institutos Nacionales de Salud y en 
Hospitales de Alta Especialidad, donde también las enfermeras universitarias especialistas han aportado con su trabajo profesional a fundar y desarrollar el tipo de servicios e instituciones del México moderno.

Las experiencias académicas de Enfermería de la UNAM, también han sido punto de referencia para el desarrollo del sistema educativo que posteriormente se estableció en las diversas regiones del país, desde 1912 que le solicitaron a la Escuela de Medicina de la Universidad Nacional de México la asesoría para diseñar programas académicos para las carreras de enfermería y de partos, hasta la época actual que los materiales educativos, publicaciones, servicios a los estudiantes, infraestructura para la docencia e investigación, planes de estudio y características de la planta de profesores, representan un modelo para un gran número de escuelas de enfermería del país.

Debemos hacer un reconocimiento a los fundadores de la En-

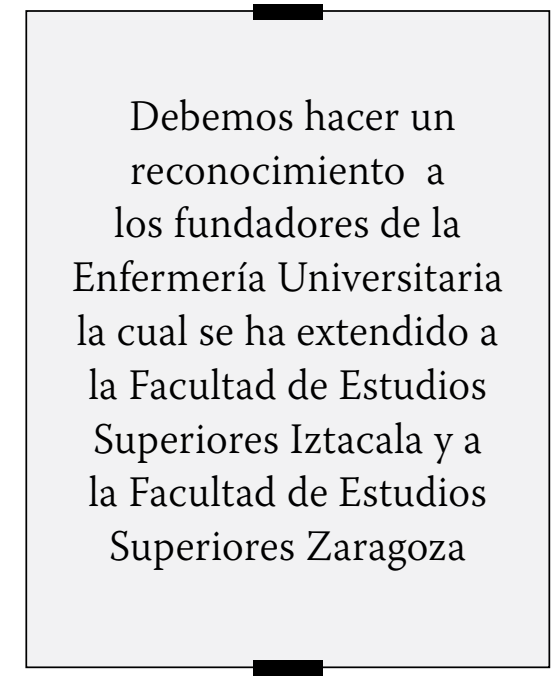

fermería Universitaria que también se ha extendido a la Facultad de Estudios Superiores Iztacala y a la Facultad de Estudios Superiores Zaragoza, que a su vez tienen contribuciones propias al sistema de Educación Profesional de Enfermería en México y aportaciones en materia de docencia e investigación que se suman a la historia de Enfermería en la UNAM, historia que se ha escrito a partir del trabajo sobresaliente de un contingente amplio de enfermeras universitarias que son inspiración y orgullo activo para la Enfermería de nuestro país.

Con este número especial de "ENFERMERÍa UNIVERSitaria" rendimos homenaje a los profesores, trabajadores, funcionarios, autoridades y alumnos, que con su esfuerzo e identidad con este proyecto educativo cumplieron en su momento en cada etapa del avance institucional, que en suma integran ahora una excelente plataforma que nos asegura el crecimiento de nuestra Escuela. De esta manera también nos unimos a la serie de festejos y actos conmemorativos sobre el CENTENARIO DE LA UNIVERSIDAD NACIONAL AUTONOMA DE MEXICO que nos remite a valorar en su justa dimensión lo que la UNAM ha hecho por la ENEO, pero también lo que la comunidad de la ENEO ha colaborado para el prestigio y proyección de nuestra Universidad. Una historia contemporánea compartida de gran trascendencia y beneficios para la sociedad mexicana.

Por Mi Raza Hablará el Espíritu. 